\title{
Maternal scaffolding during play with 12- to 24-month-old infants: stability over time and relations with emerging effortful control
}

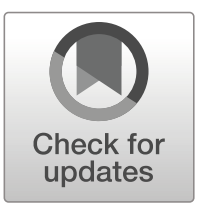

\author{
Dave Neale $^{1}\left(\mathbb{D} \cdot\right.$ David Whitebread $^{1}$
}

Received: 16 January 2018 / Accepted: 26 June 2019/Published online: 15 July 2019

(C) The Author(s) 2019

\begin{abstract}
There is evidence that parents could influence the development of their children's effortful control in infancy through social interaction. Playful interactions in infancy often involve scaffolding - i.e. the parental provision of support and modelling for problem solving and learning during play. However, previous research has found little consistency over time in this type of parental scaffolding behaviour with infants. The present study had two aims. The first aim was to use a new, tiered coding system to assess the consistency of maternal scaffolding across toys (at the same time point) and over time. The second aim was to assess whether features of parental scaffolding related to concurrent or future measures of child effortful control. Thirty-six motherchild dyads engaged in joint play when children were 12, 18 and 24 months old. The following inhibitory/effortful control tests were administered: The 'Grasping Task', an object-retrieval task using a spoon laden with food at 12 months; Two delay of gratification tasks (Snack Delay and Gift Delay) at 24 months. The Bayley Scales of Infant Development Cognitive Scale was administered at 18 months. Maternal propensity to scaffold was the scaffolding behaviour that showed most consistency across toys and over time. Maternal contingency at 12 months predicted children's effortful control at 24 months. Sequential analysis indicated that maternal contingent interventions leading to children's successful actions could be the developmental mechanism underpinning the relationship between contingency and later effortful control. Maternal behaviour during play could lay the foundations for the strategic regulation of cognition and behaviour.
\end{abstract}

Keywords Mother-infant - Object play Effortful control - Inhibitory control - Infant development Cognitive development $\cdot$ Scaffolding

Dave Neale

daveneale.phd@gmail.com

David Whitebread

dgw1004@cam.ac.uk

1 Faculty of Education, University of Cambridge, 184 Hills Road, Cambridge, UK 
Sociocultural theory proposes that metacognitive development depends on the internalization of symbolic systems through social interaction: the inter-mental use of symbols to regulate behaviour becomes an intra-mental means of regulating behaviour (Wertsch 1979, 1993, 1998). For Vygotsky $(1962,1978)$ the important distinction between humans and animals is that humans can control their behaviour using a mediator - something distinct from the task at hand but which nevertheless guides (or regulates) their activity in pursuit of a goal: 'humans [...] control their behaviour from the outside. The use of signs leads humans to a specific structure of behaviour that breaks away from biological development and creates new forms of a culturally-based psychological process' (p.40). Children who are asked to resist taking a reward for a certain time period perform better if they imagine the reward as something else (Mischel and Baker 1975): they are using something separate from the task at hand (a symbol: the imagined object that replaces the reward) and using it to regulate their behaviour in order to achieve their goal. This example also shows how Vygotsky's theory relates to an important and heavily researched aspect of psychology: inhibitory or effortful control. Indeed, some writers interpret Vygotksy's view of the human mind as essentially being about a high capacity for inhibition, one that enables people to decouple themselves from 'the types of immediate reaction to the world that are seen in animals or in people who make "unthinking" prepotent responses' (Lewis and Carpendale 2009, p.3). This 'decoupling' of the mind from automatic cognitive responses results in a level of higher order cognitive control, which could be the developmental foundation of metacognition: the ability to monitor and control one's own cognitive processes. Therefore, the early emergence of effortful control may represent the first signs of metacognitive abilities in human ontogeny.

Effortful control is related to the executive function construct inhibitory control, and many inhibitory control tasks can also be considered effortful control tasks and vice versa. The important distinction is that inhibitory control can be a reflexive, automatic process, whereas effortful control is, as the name implies, effortful, i.e. it involves the volitional, considered application of mental resources in the pursuit of a goal (Eisenberg et al. 2004). Effortful control is volitional where inhibitory control tends to be reflexive and automatic. Therefore, it is consistent with the Vygotskian view of the human mind outlined above, where the 'higher mental faculties' represent the capacity for self-regulation through a decoupling from immediate, automatic responses to the world. However, whereas the broader construct of selfregulation encompasses strategies for controlling all aspects of cognition and behaviour, effortful control refers specifically to instances where control is exerted over a prepotent or automatic response. For example, one may have a prepotent urge to consume chocolate, to express anger or frustration, to watch television instead of focus on writing an essay, or to express joy at a friend's success. Effortful control can be exerted to modulate each of these prepotent responses, and will normally be applied to limit their expression, but occasionally (as in the case of joy) one might want to enhance the emotional and behavioural expression of a prepotent response. Measures of effortful control have been developed and applied with children from 24 months and older (Kochanska et al. 2000). The aim of the present study was to explore how effortful control emerges over time in relation to mother-infant interaction across the second year of life. Based on sociocultural theory, one might expect the emergence of effortful control to be affected by exposure to adult modelling of cognitive and behavioural regulation, and the use of symbolic mediators to direct and apply cognitive resources.

The relationship between pre-linguistic interaction and the regulation of child behaviour has received much less attention than the subject of linguistic interaction and regulatory development, although broad features of interaction such as 'parental control' and 'parental 
responsiveness' have been identified as important for certain aspects of regulatory development in infancy (Karreman et al. 2006; Kochanska et al. 2008). From a theoretical perspective, Vygotsky, although he emphasised language as the prime example of regulatory symbol-use, claimed that all symbols can serve self-regulatory functions (Vygotsky 1978; Vallotton and Ayoub 2011). This theoretical position highlights the importance of external regulation in infancy as a context for the modelling of regulatory strategies and behaviours, and suggests that an important focus for empirical study is parent-child interactions in which, over ontogenetic timescales, parental regulation gives way to child self-regulation. One such type of interaction is parent-child scaffolding.

Scaffolding represents the way in which a parent guides a child's learning during a goaloriented task by offering or withdrawing support at different levels depending on the child's current developmental level and learning needs. In particular, contingent scaffolding - the provision of support only when a child needs it and withdrawal of support at other times - has been associated with the development of self-regulation and metacognition in school-age children (Wood and Middleton 1975; Wood et al. 1976; Winsler et al. 1997), although the level of support given and the emotional tone of the interaction are also important (Conner and Cross 2003; Pino-Pasternak and Whitebread 2010; Pino-Pasternak et al. 2010). The results of some research with preschool children has also suggested that parental scaffolding is related to the early development of effortful control (Lengua et al. 2014). During effective scaffolding, a parent encourages their child to be deliberative and reflective in selecting the appropriate actions to achieve the task goal, and to inhibit more reflexive and automatic responses, thereby providing a context for the development of the effortful control of behaviour and cognition.

There is a growing literature on parent-child scaffolding in the preschool years (Bernier et al. 2012; Conway and Stifter 2012; Hughes and Ensor 2009). Results suggest that even in infancy scaffolding plays an important role in the early development of executive functions, including inhibitory control - a construct closely related to effortful control. However, few of these studies look at children under 2 years old. Those that do either do not include a measure of executive functioning prior to 2-years-old (Bernier et al. 2012; Cuevas et al. 2014), or only include a global measure of scaffolding that does not facilitate sequential analysis of motherinfant behaviours, for example, a Likert-scale rating of 'autonomy support' (Bernier et al. 2010; Matte-Gagné and Bernier 2011). We are missing a more extensive assessment of early parental scaffolding that includes more factors found to be developmentally-relevant with older children, such as the specific use of directive utterances and contingent utterances and their specific temporal relations to children's activity. Through coding parent-infant scaffolding at an utterance-by-utterance level, the present study aimed to illuminate the process of early scaffolding and potentially indicate how scaffolding may influence child development. For example, do parental utterances lead immediately to children's improved performance on-task, improvement which could underpin a larger developmental trend? Or do the utterances have little immediate influence, and it is through another mechanism that they influence development on larger ontogenetic timescales?

Related to this, many studies of parent-infant scaffolding have adopted a macro, global assessment of scaffolding behaviours rather than micro-genetic, utterance-level coding. For example, global measures of maternal responsiveness have been linked with children's effortful control (Kochanska et al. 2000; Kochanska et al. 2008; Kochanska and Aksan 2004; Vallotton 2009). To really understand the social mechanisms that facilitate developmental change it is necessary to look at behaviour at the micro-level, on an utterance-by-utterance basis (Neale and Pino-Pasternak 2016). In this regard, micro-level codes can begin to address 
questions about mechanisms that macro-level coding cannot address. Although macro-level coding can identify predictive variables, it makes it hard to draw empirical conclusions about exactly why or how those variables are predictive, and so such studies often conclude by theorising why such a relationship may exist. For the present study, the main advantage of micro-level coding was to facilitate sequential analyses to examine how maternal behaviours led to infant behaviours or vice versa. In addition, we were concerned to see if capturing maternal scaffolding at a more nuanced level would result in the detection of continuity in scaffolding behaviour over time. However, there are more advantages to be derived from the level of detail micro-coding provides (for examples, see Neale and Pino-Pasternak 2016).

Finally, there appear to be no studies assessing parents' propensity to engage in scaffolding with their infants, with most designs including instructions to the parent to engage in scaffolding behaviour. Yet perhaps the simple prevalence of scaffolding in a home could exert an important influence on early development. To address this question, the present study was designed to allow parents to engage in free play or scaffolding as they chose, facilitating the inclusion of parental 'propensity to scaffold' as a potential predictor of children's effortful control development.

\section{Parental scaffolding}

Scaffolding describes the way one individual (often a parent or teacher) structures and guides the learning experience of another (normally a child) and there is now several decades' worth of evidence showing the positive impact effective scaffolding can have on the learning of school-aged children (Hammond et al. 2012; Wood et al. 1976). Specific scaffolding behaviours identified as important include directive utterances and contingency.

Directive utterances are utterances which give commands or severely limit the child's choices. Research suggests that directive utterances generally curtail the development of selfregulation (Bibok et al. 2009), but may assist cognitive development in children under three years of age (Landry et al. 2000). Despite this, there has been little to no research into how maternal directive utterances in scaffolding with infants could relate to effortful control development. There is a body of literature which explores parental discipline strategies, where a number of relations have been identified between directive discipline approaches and child compliance (Kok et al. 2012; Van der Mark et al. 2010). However, while effortful control and compliance are related, they are different constructs, as one represents the individual ability to regulate behaviour in the pursuit of goals, and the other the way in which one responds to requests from an authority figure (Spinrad et al. 2012). While the way a parent issues direct instructions to her child could be supposed to influence the extent to which the child comes to comply with such instructions, it is less clear whether or how the use of direct instructions would influence the child's ability to regulate their goal-directed behaviour more broadly. The present study included an analysis of directive utterances to address this latter point of contention.

Contingency describes the extent to which a parental intervention is contingent upon attributes of the child (for example their age, ability, and whether or not they are struggling with the task in hand). A contingent parental response is one which occurs when a child requires help of some kind, as opposed to a parental intervention which appears unnecessary because it occurs when a child is coping adequately. A contingent response will also provide the appropriate level of support to assist the child - not taking over the task completely, and not 
giving too little assistance to have any effect. We posited that maternal contingency could be particularly important for effortful control development for two reasons. The first was empirical, based on previous research findings showing its importance in scaffolding with older children (Pino-Pasternak et al. 2010). The second was theoretical, in that contingency is a means of modulating a child's response with the appropriate nuance for them to make a successful goal-directed action. A contingent response ensures the child does as much as they are capable of in pursuit of the goal, while also ensuring regular progress towards that goal, resulting in positive feedback and motivation to continue. Therefore, contingency is a means of maintaining a child's goal-directed focus, while continually emphasising the importance of their personal agency in achieving that goal. We suggest that these two things - focus on a goal and belief that one's personal agency is integral to achieving it - are central aspects of effortful control.

One study which has examined maternal scaffolding with infants on a close, micro-genetic level is that by Conner and Cross (2003) who looked at 45 mother-child dyads at four timepoints from 16 to 54 months-old. They coded children's actions as successful or unsuccessful towards the task goal, and each maternal behaviour during scaffolding based on the level of help provided to the child, from level 0 (no help) to level 6 (demonstration, considered the highest level of support). From this, maternal contingency could be calculated based on the extent to which a mother increased the level of support following child failure and decreased support following child success. They also generated a region of sensitivity variable for each mother, which was correlated with contingency, and which represented the extent to which a mother intervened at a level of support just below that at which her child normally succeeded. Maternal use of the region of sensitivity predicted children's success during scaffolding, and children's success during scaffolding predicted their independent success at other similar tasks used as outcome measures. However, Conner and Cross (2003) did not assess effortful control or any other broad measures of executive function, so their study does not show how scaffolding could relate to broader aspects of development.

Interestingly, Conner and Cross (2003) found no stability over time in the various maternal scaffolding variables they assessed, including contingency, with a longitudinal sample of infants from 16 to 54 months old. One possible explanation is that the scaffolding coding only accounted for one unitary goal (complete the task) and failed to distinguish between different scaffolding sub-goals, such as piece selection, piece placement and error correction. The sub-goals necessary to complete a task are very different in terms of the cognitive demands and types of support given - for example, placing a ring onto a ring toy requires very different cognitive processes and parental support than identifying and removing a ring placed in error, but no such distinction was made in Conner and Cross' (2003) coding scheme. It could be when examining scaffolding over time only measures that are fine-grained enough will capture any underlying continuity.

Finally, although some research, such as that by Conner and Cross (2003), has looked at stability in maternal scaffolding with infants over time, there appear to be no studies assessing synchronous stability in behaviour across different tasks/toys. If maternal scaffolding behaviour is not consistent across toys or across time, it would suggest that it does not represent a robust aspect of maternal interactional style. Alternatively, if there is stability across toys, scaffolding behaviour in infancy could be considered a robust aspect of maternal style - at least within limited time-frames - and any lack of stability over time is either the result of change in behaviour or the failure of coding schemes to capture the underlying continuous 
elements. Overall therefore, the stability or fluidity of maternal scaffolding behaviour during infancy is an area that is still under-researched.

Based on the preceding review of the literature, the aims of the present study were: 1) to assess consistency in features of maternal scaffolding over time and across toys, and 2) to examine whether features of maternal scaffolding predicted children's effortful control at 24 months.

The present study was a longitudinal design, with time-points when infants were 12, 18 and 24 months old. Mothers were chosen as the focus of the research rather than fathers because the majority of research into early infant development and social interaction has focused on mothers, and some studies have suggested mothers play a more important role in infancy when assessing child outcomes (Conner et al. 1997; Nordling et al. 2016).

\section{Method}

\section{Participants}

A convenience sample of mothers and children were recruited through local groups and advertisements. Participants visited the lab when children were 12, 18 and 24 months old. The sample size at 12-months was 36 (18 girls), at 18-months it dropped to 34 (18 girls), and at 24-months to 33 (17 girls). Although this sample size was relatively small, it exceeded that of other similar longitudinal studies (e.g., Rudek and Haden 2005, with 21 dyads) and was comparable with Conner and Cross's (2003) sample of 39 dyads after attrition. Participants predominantly identified themselves and their child as being of white British ethnicity/ nationality ( 32 of 36 ), with a family income in the range of $£ 36-50,000$ (14 of 36) or £5180,000 ( 10 of 36). Most of the mothers had an undergraduate or postgraduate degree (26 of 36) and most of the children had no siblings at the start of the study ( 26 of 36 ). Those children with siblings all had one older sibling.

\section{The grasping task (12-months)}

A new task to assess children's inhibitory/effortful control was developed during an earlier phase of this study, as reported in Neale et al. (2018). The child was seated in a high chair. A spoon of food was placed on the high chair tray for the child to pick up, with the spoon's orientation alternating with each placement. Placements continued for a minimum of 8 (4 each orientation) and a maximum of 12 (6 each orientation). Each placement was coded based on whether the child first reached with the handle-side hand, or, due to a failure to inhibit use of their preferred hand and/or the hand used on the previous trial, reached with the bowl-side hand. A trial consisted of one pair of placements, i.e. one placement in each orientation. A ratio score was generated for each child, as the ratio of trials in which the infant reached with the handle-side hand for both spoon orientations (and therefore clearly inhibited use of their bowl-side hand) over all trials. Furthermore, this task appears to capture effortful control, in that some infants begin to reach with the bowl-side hand, notice their error, and switch to the handle-side hand, i.e. the inhibitory control applied is (at least in some cases) volitional rather than automatic. For full details on development, administration and coding of this task see Neale et al. (2018). 


\section{The Bayley scales of infant and toddler development III: Cognitive scale (18-months)}

It was considered useful to include a measure of cognitive development to assess whether any predictive mother-infant interaction variables were predictive of effortful control specifically or were also predictive of cognition more generally. The BSID is a widely used standardized test of infant development with five scales and established validity and clinical relevance (Bayley $2006 \mathrm{a}$, b). For this study, primarily due to time limitations, only the cognitive scale was administered. Children received a standardized score between 0 and 20 which became the variable BSID:CS.

\section{Effortful control delay tasks (24 months)}

Gift Delay and Snack Delay were administered using the procedures outlined in the Effortful Control Manual (Kochanska and Boldt 2013).

Snack Delay. The child was shown a bell and some chocolate and told they had to wait until the researcher rang the bell before they could eat the chocolate. Once the child confirmed that they understood a practice trial was conducted. The researcher then administered four trials with delays of 10, 20, 30 and $15 \mathrm{~s}$. Half way through the trial time the researcher lifted the bell but did not ring it. For these trials, the child could eat or not eat the chocolate as they chose. For each trial, the child was allocated a score as in Kochanska et al. (2000), ranging from 0 if the child ate the chocolate before the bell was lifted; to 4 for waiting the whole time without touching the chocolate or the bell. An average score was generated for each child from the scores on all 4 trials.

Gift Delay. The child's mother was seated in the corner of the room. Mothers were told that they should try not to interact with their child except to say they were busy. The child was seated at a table and the researcher told them he had a present for them that he was going to wrap. He turned the child's chair around and asked them not to peep while he wrapped the gift. With the gift almost fully wrapped the researcher said he needed to get some tape and asked the child not to look at the gift while he was gone. Then he left the room for three minutes, and the child's behaviour was coded as in Kochanska et al. (2000), by allocating a score from 1, meaning the child opened the gift, to 4 if they never even touched it. Scores were standardized and combined into one gift delay variable.

A good level of inter-rater reliability for the Effortful Control Battery delay tasks has been established in previous research (Kochanska et al. 2000). To ensure reliability in the present study a second rater coded $10 \%$ of the data from each delay task: Kappa was 1 for the Snack Delay and .97 for the Gift Delay. Following Kochanska et al. (2000), the scores for Snack Delay and Gift Delay were standardized and combined to create one composite delay tasks variable.

\section{Dyadic play (12, 18 \& 24 months)}

Mother and infant were presented with a ring toy with a giraffe's head at every time-point. At the 12-month time-point dyads also spent time playing with stacking cups. The researcher asked mothers to play with the toy with their child just as they would do at home and then left 
the room. The play session was ended after $5 \mathrm{~min}$, or when the child evidently became bored and disengaged with the toy. Each session was videotaped for coding and analysis.

\section{Development of the dyadic play coding scheme}

Coding of state events The present study aimed to assess the extent to which mothers chose to engage in scaffolding behaviours, a variable named propensity to scaffold. This meant that the first stage of coding was to identify the amount of time each mother spent scaffolding during the interaction. To do this, the dyadic play interactions were first coded as two mutually-exclusive state-events - non-shared attention (either mother or infant was not looking at or interacting with the toy) or shared-attention (i.e. both mother and infant were looking at or interacting with the toy). State events capture behavioural changes in a continuous unbroken stream, and so every moment of the dyadic interaction was coded as either shared or non-shared attention. Episodes of shared-attention were then coded into two further mutually-exclusive state-events - shared-attention: scaffolding or shared-attention: other.

Scaffolding was defined as the presence of explicit goal-directed support from the mother, and was deemed to begin from the first goal-directed intervention and last until the mother performed any action that suggested she was no longer interested in helping her child place a cup or ring. Note that we were only interested in goal-directed scaffolding, and not other forms of teaching (e.g., teaching colours), because effortful control is a means of regulating goaldirected activity. Behaviours that occurred under shared-attention: other included any interaction with no focus on the goal of ring or cup placement, such as using rings as bracelets, balancing rings on heads, rolling rings, or singing songs. Only episodes of shared attention: scaffolding were coded using the scaffolding scheme. Because the amount of time spent scaffolding would vary for each dyad, the resulting variables were calculated as percentages of interventions/actions rather than a count of total behaviours during the interaction (which may simply reflect differences in the time spent scaffolding).

Scaffolding coding: Piloting and development The approach to coding mother-infant scaffolding used by Conner and Cross (2003) was deemed an appropriate way to capture behaviour at the micro-genetic level, meaning that coding could be grounded in specific observable interventions (by the mother) and actions (by the child). The pattern of these behaviours in the interaction could be used to generate primary scaffolding variables. Although Conner and Cross (2003) did not look at maternal directiveness, maternal interventions as coded in their scheme could theoretically be classified as directive when they explicitly instruct the child to perform an action.

However, during piloting some issues were identified with applying the Conner and Cross (2003) scheme, as the levels as described can conflate what are very different actions. For example, level 4 is 'identifies material or placement', suggesting that each of these acts carries the same semiotic and instructional weight. But when building a tower (as in Conner and Cross 2003), the rule 'one block goes on another' which is one instance of identifying placement, is quite different, and substantially less complex than the rule 'blocks go on each other in a specific order', which is another instance of identifying placement. Furthermore, identifying the material (piece) indicates that the order of placement matters - i.e. a specific piece is the correct one - and as such places demands on the child to understand the goal of ordering pieces. By contrast, simply indicating where the piece should be placed does not necessarily indicate anything about ordering, and instead only communicates the goal of placing pieces 
(regardless of order). To accurately capture the nuances of parental scaffolding in infancy it may be necessary to account for these different sub-goals.

From pilot data, three common sub-goals were identified in scaffolding with the ring toy and stacking cups. These were (in increasing order of cognitive demand) piece placement, piece selection, and error correction. Piece placement represents the goal of placing a ring or cup onto the pole or another cup. At 12-months this goal appeared to be fairly challenging for most of the infants in piloting, but by 24-months none of the infants struggled to place rings or cups. Piece selection represents the ordering of pieces. In piloting, this goal was challenging for infants at all ages, although one 24-month old had no problem correctly selecting pieces for the ring toy. Error correction represents identifying and removing a ring or cup that has been placed in error - i.e. not in the correct order. In piloting, error correction was challenging for infants of all ages, and even with maternal assistance many infants still struggled. The Conner and Cross (2003) coding scheme was adapted to account for these three sub-goals, by splitting it into three parallel strands ('zones') of coding (one for each sub-goal). For each zone, maternal interventions were described and given levels, and child successful actions were defined, based on the pilot data.

Scaffolding coding: Process The initial phase of state-event coding resulted in the identification of specific periods of scaffolding for each dyad, and only these periods were then coded using the scaffolding coding scheme. When coding scaffolding behaviour, each zone (subgoal) of the interaction was coded separately, meaning for each scaffolding interaction there were three parallel streams of coding tracking maternal scaffolding and child performance in relation to the sub-goals of piece placement, piece selection and error correction. In essence, each scaffolding period was coded three times: once for how the mother scaffolded piece placement, once for how she scaffolded piece selection, and once for how she scaffolded error correction. As in Conner and Cross (2003) coding was conducted using a turn-based procedure, so that after every maternal intervention the child was always given a code for either successful action or unsuccessful action / no action, and after every child action mothers were allocated an intervention code at the appropriate level, which could be level 0 (no intervention). Based on the pilot data, which showed that children and mothers often paused and thought for a few seconds before responding to the other's behaviour, only gaps of over $10 \mathrm{~s}$ were considered to end the turn-based sequence. Once the sequence had ended, a new turn sequence began with the next child action or maternal intervention. The resulting dataset therefore comprised three parallel streams of sequential, turn-based (mother-infant-motherinfant) codes for each dyad. An overview of the coding scheme is shown in Table 1 and the full coding manual is available from the first author.

Inter-rater reliability A second rater coded $12 \%$ of the dyadic play data from each time-point with each toy. Agreement for state-event coding was 94\%. There was 92\% agreement between the two raters about which maternal utterance represented the start of scaffolding.

For the ring toy dyadic play, the unitising agreement (i.e., agreement about which behaviours should be coded) for mothers' interventions was $86 \%$ and Kappa for coding agreement was .74, and for children's actions unitising agreement was $91 \%$ and Kappa for coding agreement was .89 . For the stacking cups dyadic play, unitising agreement for mothers' interventions was $83 \%$ and Kappa for coding agreement was .72, and for children's actions unitising agreement was $90 \%$ and Kappa was .86 . 


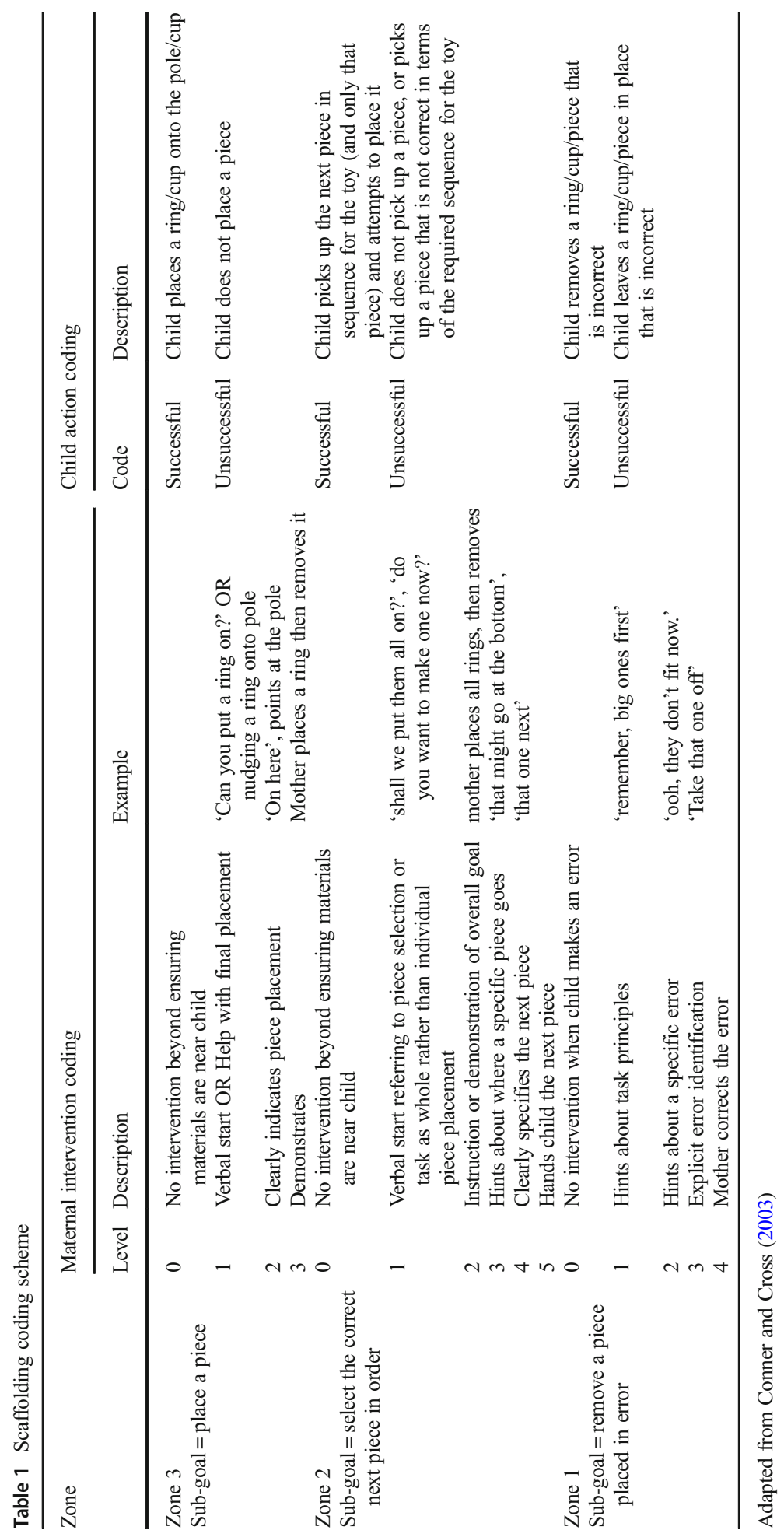


Creation of variables Propensity to scaffold was intended to represent a mother's propensity to engage in goal-oriented play behaviours with an explicit instructional component; the converse was to engage in less structured play behaviours, for example, spinning rings, hiding cups, or naming colours. It was calculated for each mother as the percentage time spent in shared attention: scaffolding out of all time spent in shared attention. Any time periods of nonshared attention were ignored, because it seemed reasonable to suppose that if a child's attention was not focussed on the toy their mother did not have the option of engaging them in a scaffolding interaction.

Child performance was intended to capture children's performance during scaffolding to assess whether any relationship between scaffolding variables and effortful control could be explained by the way children's cognitive abilities affected maternal scaffolding, rather than the other way around. For each child, the total number of successful actions (across all zones) was tallied, and the percentage (out of total actions) was calculated to generate a child performance variable.

Contingency was intended to represent the extent to which a mother adjusted her level of support appropriately based on her child's immediate needs. Conner and Cross (2003) use the term 'appropriate shifting' for this variable, and they calculated it as the percentage of parental interventions representing an increase of support following child failure or a decrease support following child success. Based on the same principles, in the present study each maternal intervention was defined as contingent or non-contingent using the following criteria:

- Following a successful action by the child the mother either maintained her current level of support or reduced her level of support.

- Following an unsuccessful action by the child the mother increased her level of support.

Once interventions were coded as contingent or non-contingent the percentage of contingent interventions out of all interventions was calculated to generate a contingency score for each mother.

Directiveness was intended to represent the extent to which a mother gave explicit directions to her child, as opposed to suggestions, hints or explanations. In each zone, every

Table 2 Descriptive statistics for all variables

\begin{tabular}{llllll}
\hline & Mean & Std. deviation & Median & Observed range & Inter-quartile (25th-75th) \\
\hline Propensity to scaffold, 12 months & 72 & 23 & 79 & $10-99$ & $53-92$ \\
Propensity to scaffold, 18 months & 80 & 25 & 92 & $0-100$ & $63-100$ \\
Propensity to scaffold, 24 months & 71 & 26 & 75 & $0-100$ & $58-93$ \\
Contingency, 12 months & 32 & 17 & 33 & $0-76$ & $20-42$ \\
Contingency, 18 months & 56 & 11 & 57 & $31-76$ & $50-63$ \\
Contingency, 24 months & 49 & 17 & 49 & $15-87$ & $40-58$ \\
Directiveness, 12 months & 19 & 16 & 16 & $0-61$ & $6-31$ \\
Directiveness, 18 months & 18 & 11 & 15 & $2-42$ & $8-28$ \\
Directiveness, 24 months & 10 & 12 & 8 & $0-50$ & $1-17$ \\
Child performance, 12 months & 37 & 24 & 37 & $0-90$ & $17-56$ \\
Child performance, 18 months & 70 & 11 & 69 & $41-100$ & $65-76$ \\
Child performance, 24 months & 44 & 19 & 43 & $6-76$ & $27-57$ \\
Grasping Task Ratio & 0.56 & 0.28 & 0.50 & $0.17-1.00$ & $0.33-0.80$ \\
Delay Tasks & 0.00 & 1.00 & -0.14 & $-1.61-1.16$ & $-0.64-0.59$ \\
Bayley Scales: CS & 11.46 & 1.84 & 11.00 & $9-15$ & $10-13$ \\
\hline
\end{tabular}




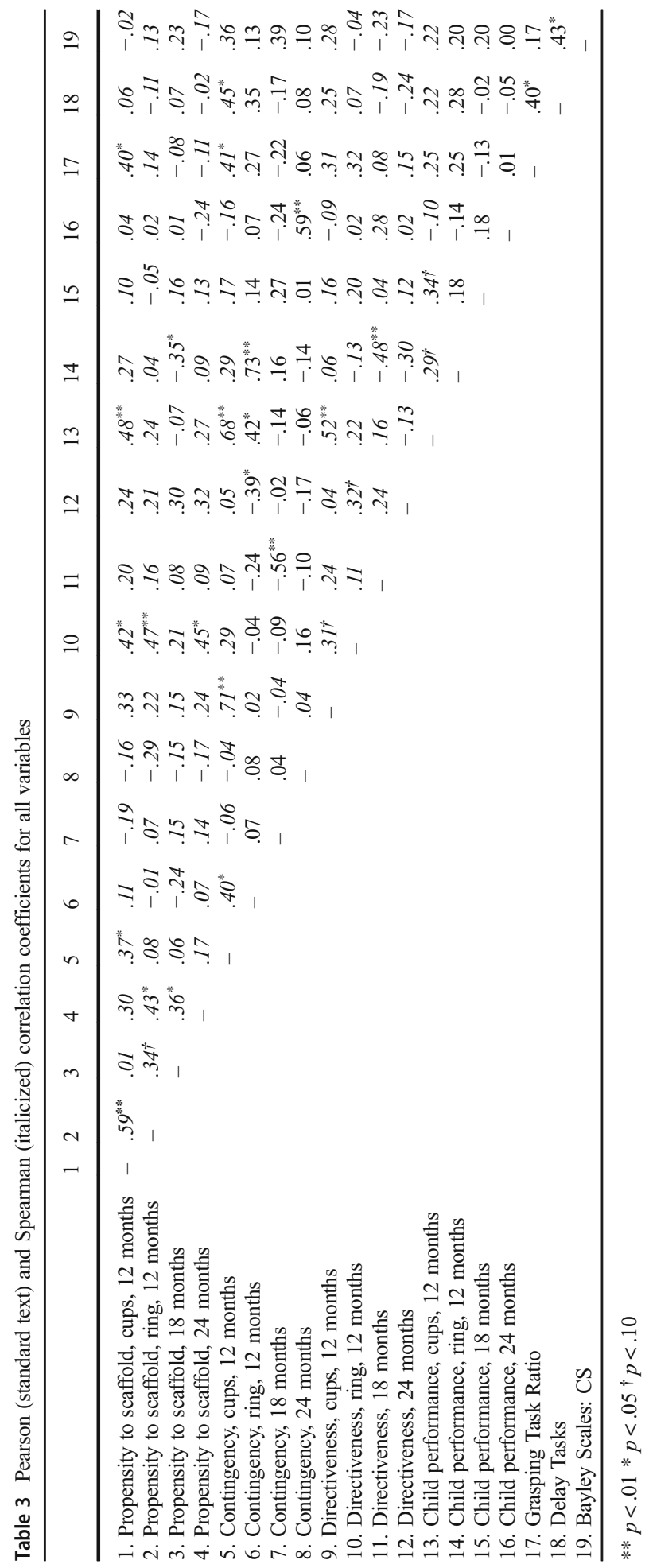


level that involved giving the child an explicit direct instruction was labelled as directive, as follows:

- Zone 3 (piece placement), level 2: Clearly indicates where to place the piece.

- Zone 2 (piece selection), level 4: Clearly indicates the next piece.

- Zone 2 (piece selection), level 5: Hands the child the next piece or otherwise ensures correct piece selection.

- Zone 1 (error correction), level 3: Clearly indicates that the error needs correcting.

For each mother, the total number of directive interventions (across all zones) was tallied, and the percentage (out of total interventions) was calculated to generate a directiveness variable.

\section{Results}

\section{Statistical approach}

Multiple tests were conducted. However, as we have stated elsewhere (Neale et al 2018), due to the many problems identified with corrections for multiple comparisons, these techniques were not applied (Gelman et al. 2012; Nakagawa 2004; Perneger 1998). Instead, our concern was to present the data as fully and accurately as possible, and to treat significant results as indicators of potentially interesting relations between variables. When interpreting results the overall pattern of significance and effect sizes were considered, and, in most cases, only multiple correlations with a given variable was taken as good evidence of a relationship (as specified in the individual analyses below), meaning family-wise error-rates were held below .05 . With regressions, our primary aim was to assess the magnitude of coefficients as accurately as possible. ${ }^{1}$

\section{Descriptive statistics}

Descriptive statistics for all variables are reported in Table 2. Note that all dyadic variables (i.e., all variables except the bottom three in the table) are percentages. Some variables did not meet the assumptions for parametric analysis, so non-parametric tests were used in any correlational analyses involving those variables. Correlations related to the research questions are presented in the next section.

\section{Research question 1: How consistent are features of scaffolding across toys and over time?}

Correlations between all study variables are shown in Table 3. For each individual scaffolding variable, bivariate correlational tests were run to test whether it showed consistency across toys and

\footnotetext{
${ }^{1}$ Austin and Steyerberg (2015) used Monte Carlo simulations to determine that for accurate estimation of coefficients in linear regression, the minimum sample size is only two subjects per variable, as long as the adjusted value for $R^{2}$ is used. However, Green (1991) concludes that required sample sizes for estimation of partial correlation coefficients tend to be larger, and that with a sample size of 31 , more than three predictors would compromise power to detect even a large effect. Consequently, with a sample size of 33 to 36 for each time-point, we limited the number of predictors in each regression we conducted to a maximum of three.
} 
over time. These tests were considered the most appropriate as we were interested in the associations between all three variables, without controlling for each other (meaning multiple regression and partial correlation were not appropriate). As stated above, when considering consistency in scaffolding over time, our focus was on interpreting the pattern of results, and a single significant correlation out of three would not be considered convincing evidence for consistency over time in that variable. As at least two significant correlations at .05 were required out of three, the error rate for each set of tests for continuity over time with each scaffolding variable was .007 (making the total family-wise error rate across all four scaffolding variables below .029). For consistency across toys, only the presence of at least two significant correlations across scaffolding variables would be treated as reasonable evidence (meaning the family-wise error rate across all four scaffolding variables was .014). The presence of a single significant correlation for only one of the four scaffolding variables would be treated as very tentative evidence of any kind of consistency across toys.

There was consistency in mothers' propensity to scaffold both across toys and over time. Parents who spent more time scaffolding at 12-months and 18-months also spent more time scaffolding at 24-months, suggesting that the propensity to scaffold variable may capture a relatively robust aspect of maternal interaction style. Maternal contingency was consistent across toys at 12-months but exhibited no consistency over time. For directiveness, there was very tentative evidence of consistency across toys in the form of a marginally significant correlation with a medium effect size, but little evidence of consistency across time. As with directiveness, there was very tentative evidence of some consistency in child performance during scaffolding across toys, but little evidence of consistency over time.

\section{Relations between maternal scaffolding and child performance}

Three regression analyses (one for each time-point) were conducted to see whether the maternal scaffolding variables were related to child performance during play (Table 4). Again, across the three regressions, only significant relationships between a given scaffolding variable and child performance at multiple time-points would be treated as good evidence of a relationship, meaning the family-wise error rate for each scaffolding variable was .007 , and the total error-rate for all three regressions was below .029 .

Table 4 Summary of regression analyses for maternal scaffolding variables predicting child performance at the same time-point

\begin{tabular}{llllll}
\hline & & $\mathrm{B}$ & $\mathrm{SE}(\mathrm{B})$ & $\beta$ & $\mathrm{sr}^{2}$ \\
\hline 12 months & Propensity to scaffold & 0.19 & 0.13 & .18 & .02 \\
& Contingency & 109.80 & 15.89 & $.78^{* * *}$ & .57 \\
& Directiveness & -32.51 & 18.96 & -.22 & .03 \\
& Adjusted R & & $.60^{* * *}$ \\
18 months & Propensity to scaffold & -.06 & .08 & -.12 & .01 \\
& Contingency & 55.40 & 23.49 & $.52^{*}$ & .17 \\
& Directiveness & 41.64 & 23.40 & .39 & .09 \\
& Adjusted R & & & .09 \\
& Propensity to scaffold & -21.12 & 10.87 & -.29 & .08 \\
& Contingency & 69.40 & 16.71 & $.61 * * *$ & .36 \\
& Directiveness & 33.99 & 24.96 & .21 & .04 \\
& Adjusted R R & & & $.38^{2 * *}$ \\
\hline
\end{tabular}

12-month scores are a composite of scores for the ring toy and the stacking cups.

$* * * p<.001 * * p<.01 * p<.05$ 
The only scaffolding variable related to child performance across time-points was maternal contingency. However, it was considered that the identified relationship could be the result of children's successful actions leading to maternal contingent responses, rather than maternal contingency supporting children's activity. The micro-level coding scheme adopted in this study allowed for these two possibilities to be disentangled, through a sequential analyses that indicated whether maternal contingent interventions led to children's successful actions or vice versa. One set of analyses assessed the frequency with which contingent interventions led to children's successful actions, and a second set assessed the frequency with which children's successful actions led to contingent interventions. Frequency counts were subjected to Chisquare analysis to see if the frequencies with which specific behaviours followed or preceded each other were significantly different to what would be expected by chance. Note that both variables were binary: each maternal intervention in the dataset was either contingent or noncontingent, and each child action in the dataset was either successful or unsuccessful. Consequently, every maternal intervention led to either success or failure by the child, and by chance one would expect each to occur with the same frequency with which it occurred in the whole dataset. Chi square tells us whether any differences in these frequencies (e.g. contingent interventions leading to success $82 \%$ of the time and non-contingent leading to success $79 \%$ of the time) are statistically significant. Therefore, the results indicated whether maternal contingent interventions led immediately to children's successful actions more often that would occur by chance alone, and vice versa. The sample sizes for the analyses were 34 dyads and 707 mother/infant behaviours at 12 months with the ring toy; 34 dyads and 400 mother/infant behaviours at 12 months with the stacking cups; 30 dyads and 1389 mother/infant behaviours at 18 months; and 32 dyads and 1012 mother/infant behaviours at 24 months.

The results are presented in Figs. 1 and 2. Contingent interventions led to successful actions by the child significantly more than non-contingent interventions at 12-months and 18-months (despite the absence of a significant correlation at 18 months), but not at 24-months. Interestingly, children's successful actions led to a contingent intervention by their mother significantly more than unsuccessful actions with both toys and at every time-point, meaning that mothers were more likely to withdraw support when their child was doing well than they were to increase support when their child was struggling. Therefore, the relationship between contingency and child performance in the data was the result of both contingent interventions influencing child performance and child performance influencing maternal interventions. However, considering that contingent interventions at 24-months did not lead to significantly more successful child actions it seems that the large correlation between contingency and child performance at 24-months is solely the result of mothers withdrawing support following child success, rather than any effect of contingency on child performance at that time-point.

\section{Research question 2: Do features of maternal scaffolding during goal-oriented play relate to the development of effortful control?}

In order to select variables for a regression analysis, correlational analyses were conducted for all the scaffolding variables at each time point and all child effortful control and cognitive functioning variables. There were some significant relationships involving the 12-month scaffolding variables: 12-month contingency correlated with Grasping Task scores, $r=.36$, $p=.04$, and delay task scores, $r=.46, p=.01$; and 12-month directiveness correlated with Grasping Task scores, $r_{s}=.38, p=.03$. There were no significant correlations at 18 or 


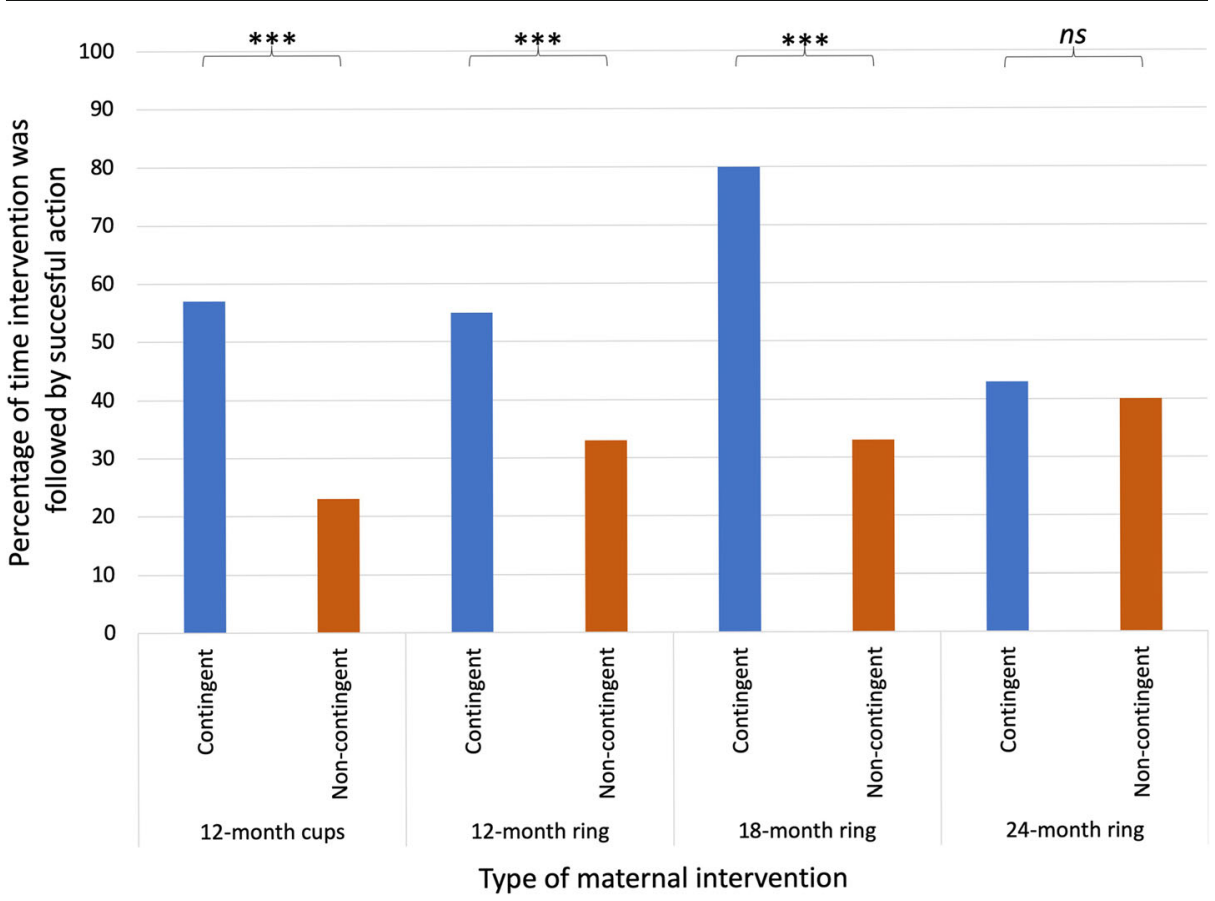

Fig. 1 Frequency (in percent) with which parental contingent and non-contingent interventions led to successful actions by the child. $* * *$ difference is significant at $p<.001$

24 months. Appropriately, the two variables which correlated with effortful control - contingency and directiveness - were the two variables with established theoretical and empirical

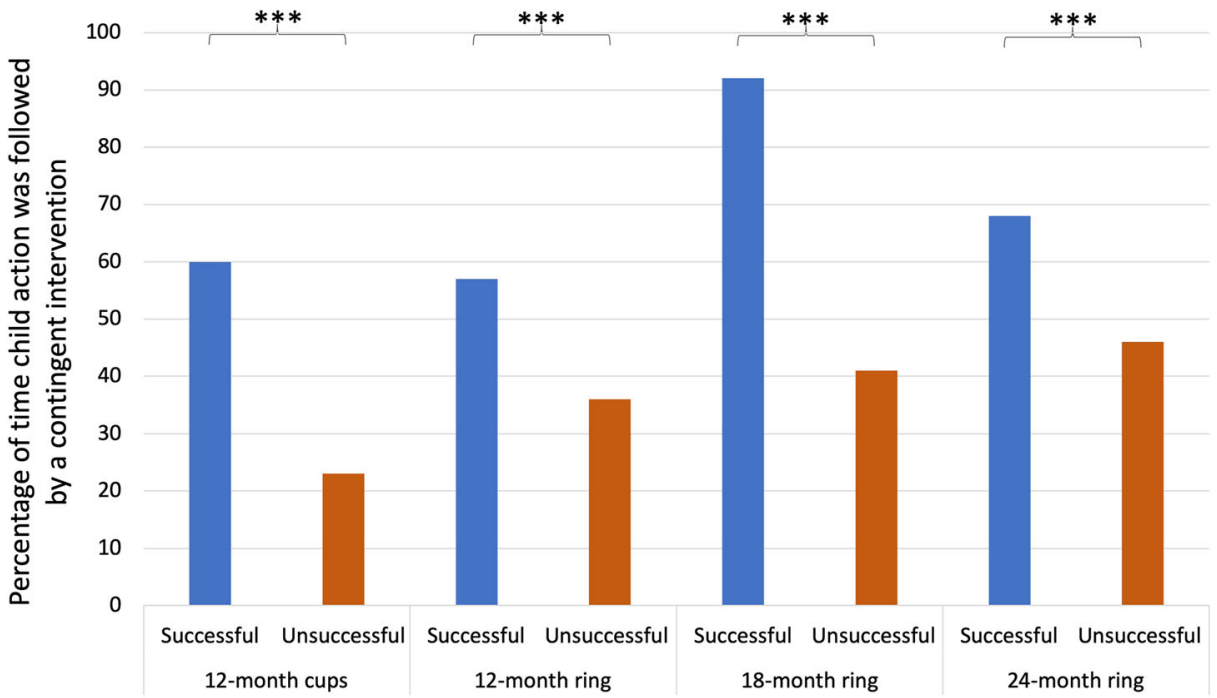

\section{Child action}

Fig. 2 Frequency (in percent) with which children's successful and unsuccessful actions led to parental contingent interventions. $* * *$ difference is significant at $p<.001$ 
links to child development. Consequently, including them in a regression analysis was justifiable based both on the current dataset and on existing research literature. To assess how maternal scaffolding may affect effortful control development over the second year of life, a regression analysis was run with 24-month effortful control (delay task scores) as the dependent variable, contingency and directiveness as predictors, and controlling for 12month effortful control (The Grasping Task). Results are shown in Table 5.

The model was significant, meaning a combination of 12-month effortful control, 12-month contingency, and 12-month directiveness explained $21 \%$ of variance in children's 24-month effortful control. No individual variable was a significant predictor, but contingency approached significance and had the highest Beta, while directiveness appeared to contribute very little to the model, with an $s r^{2}$ of zero (meaning it explained no remaining variance in 24month effortful control once the other two variables were taken into account). As directiveness appeared superfluous to the model, the influence of maternal contingency alone on 24-month effortful control was assessed with a partial correlation analysis on 12-month contingency with 24-month effortful control (delay tasks) controlling for 12-month effortful control (Grasping Task ratio). The result, $r=.38, p=.052$ (two-tailed), $R^{2}=.14$, suggested that contingency at 12-months had a medium effect on effortful control development over the subsequent year and explained $14 \%$ unique variance in effortful control at 24-months.

\section{Grouping mothers based on consistent use of contingency}

It was considered that there could be broad differences in maternal styles obscured by the statistical group-level analysis. Landry et al. (2003) found that parents could be grouped based on how consistent they were in 'sensitive responding' (a global measure of parental behaviour with some similarities to contingency) and that the most consistent group had children with superior outcomes. The contingency data were studied in an attempt to identify any patterns indicating consistency or inconsistency over time that may be overlooked in a group-level statistical analysis. It became apparent that while some mothers exhibited a moderate to high level of contingency at every time point, others were highly erratic in how contingent they were, ranging from no contingent interventions at one time-point to a high proportion at another. Specifically, there seemed to be a natural divide in the data between mothers who used at least $30 \%$ contingent utterances at each time point and those who were more varied in their contingency scores. The value of $30 \%$ was used because it allowed the dataset to be split exactly in two, and so it was equivalent to a median split, but was based on a pattern of values over time rather than the median of an individual variable. Note that the figure of $30 \%$ is not, in itself, particularly important - rather, it was used to divide mothers into equal groups which differed in how consistently contingent they were. Based on this difference in contingent

Table 5 Summary of regression analyses for scaffolding variables at 12 months predicting effortful control at 24 months

\begin{tabular}{llllll}
\hline & & B & SE (B) & $\beta$ & $\mathrm{sr}^{2}$ \\
\hline \multirow{2}{*}{12 months } & The Grasping Task (control) & 0.90 & 0.56 & .31 & .08 \\
& Contingency & 1.72 & 0.88 & .36 & .11 \\
& Directiveness & -.24 & 0.94 & -.05 & .00 \\
& Adjusted R ${ }^{2}$ & & & $.21^{*}$ \\
\hline
\end{tabular}

$* p<.05$ 
behaviour over time mothers were divided into the 'consistent contingent' group ( $n=18)$, who were rated as $30 \%$ contingent or more at all three time-points, and the 'inconsistent contingent' group $(n=18)$, who were rated as less than $30 \%$ contingent on one or more time-points.

A series of independent samples t-tests revealed differences in children's scores on all three measures of psychological functioning. On the Grasping Task the consistent group $(M=.68$, $S D=.21)$ scored higher than the inconsistent group $(M=.44, S D=.29), t(31)=-2.75, p=.01$ (two-tailed). On the delay tasks the consistent group $(M=.38, S D=.78)$ scored higher than the inconsistent group $(M=-.47, S D=.55), t(29)=-3.51, p=.001$ (two-tailed). On the BSID:CS, the consistent group $(M=12.07, S D=2.02)$ scored higher than the inconsistent group $(M=$ $10.44, S D=0.88), t(22)=-2.71, p=.01$ (two-tailed). Note that although three t-tests were conducted, our statistical approach was based around assessing the pattern of significance. We expected contingency to relate to both measures of effortful control (The Grasping Task and Delay Tasks) and potentially to the Bayley Scales scores (given prior evidence linking contingency and cognitive functioning). The family-wise error rate for a significant difference on all three measures is below .05 (estimated family-wise error-rate $=.05 \times .05 \times$ $.05=.000125)$, as it is for both effortful control measures $(.05 \times .05=.0025)$. (Furthermore, although we do not agree with it as an approach, if the three tests were subjected to a Bonferroni correction, they would all remain significant at $p<.05$ ).

Given substantial evidence that parental behaviour often has the strongest effect on the development of the most at-risk children (Jaffee 2007; Landry et al. 1997; Landry et al. 2001; Landry et al. 2003) it was considered potentially insightful to explore whether the developmental trajectories of children who began the study with low effortful control differed depending on whether or not their mother was consistent or inconsistent in her contingency. The data were examined to see if any pairs of children from the two different groups began the study with the same below-the-mean Grasping Task scores at 12-months. Three pairs were identified and the associated Grasping Task ratio scores were standardized such that the mean was 0 and the standard deviation was 1 so that they could be compared to the 24-month delay task scores (which had already been standardized). The change in standardized effortful control scores over time for children from each group is illustrated in Fig. 3.

All three children with consistently contingent mothers showed a similar trajectory of development and ended the study above the mean for effortful control and with scores approximately one standard deviation higher than at the start of the study. By contrast, the three children with inconsistently contingent mothers showed either a small degree of improvement over time or a decline, and all ended the study below the mean for effortful control.

\section{Discussion}

This study had two main aims: 1) to assess consistency in features of maternal scaffolding over time and across toys, and 2) to examine whether features of maternal scaffolding predicted children's effortful control at 24 months.

Regarding consistency in scaffolding over time, the results showed that from 12 to 24 months mother's propensity to scaffold was a relatively consistent aspect of her scaffolding style. There was also some evidence of consistency in scaffolding with the two toys. The identification of some continuity in scaffolding variables suggests that the method of measurement has to be appropriate to capture stability over time. In the present study, categorising scaffolding based on the specific sub-goal (piece placement, piece selection or error 
correction), coded a micro-genetic level, resulted in the detection of some continuity, which the methodological conflation of the different goals by Conner and Cross (2003) failed to detect.

In agreement with the findings of Conner and Cross (2003) there was no consistency in contingency over time. However, there was consistency in contingency across toys, and subsequent study of the data revealed mothers could be grouped based on whether their contingency was consistently above a certain level across the year. Results indicate that maternal contingency during play seems to vary on a quantitative level over time, perhaps depending on variables such as mother or child mood, time of day, etc., but the specific way in which it varies may be different for different mothers. Grouping mothers based on this difference in variation led to the identification of group differences in children's effortful control and cognition (discussed below). This reflects the findings of studies exploring other aspects of maternal behaviour. The most meaningful way to assess the impact of maternal

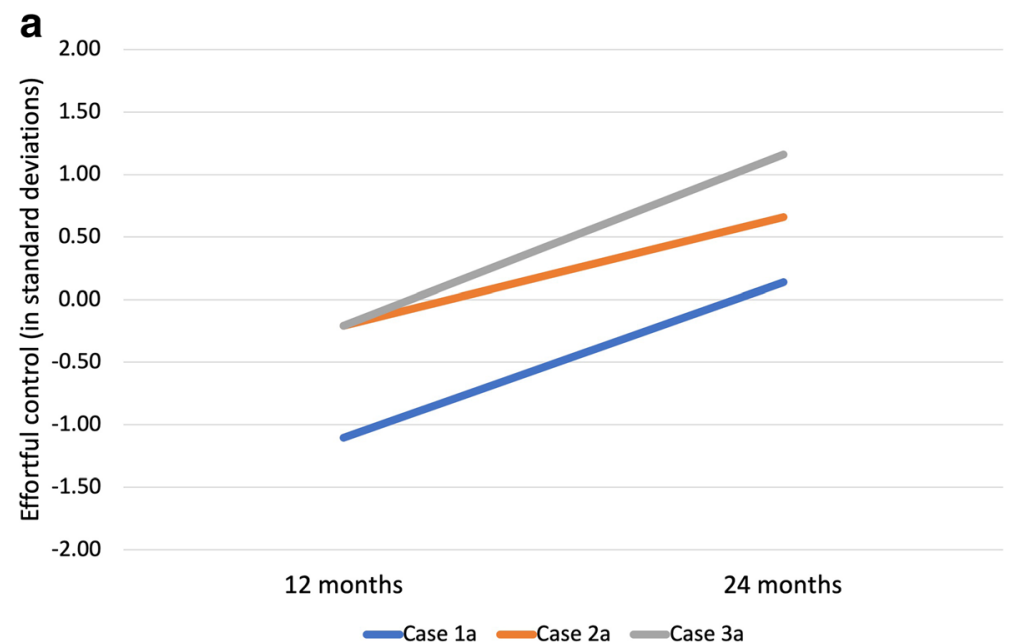

b

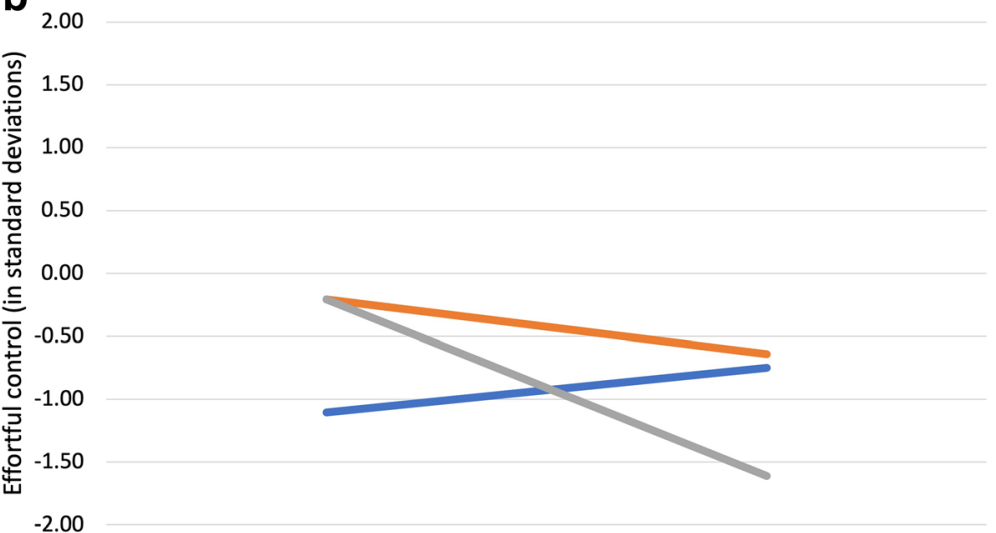

12 months

24 months

Case $1 \mathrm{~b}=$ Case $2 \mathrm{~b}=$ Case $3 \mathrm{~b}$

Fig. 3 Change in standardized effortful control from 12 months (Grasping Task ratio) to 24 months (delay task scores) in children matched for below-the-mean Grasping Task ratio score at 12 months, with consistently contingent parents (a) and inconsistently contingent parents (b) 
sensitivity, for example, is not on an individual quantitative level, but instead to group mothers based on how consistent they are in their sensitivity over time (Landry et al. 2003).

With significance or marginal significance, all scaffolding variables exhibited consistency across toys at 12-months. Therefore, the overall pattern of results suggested that play with a different toy appears to exert less influence over dyadic scaffolding behaviour than temporal change of 6 months or more. However, although the two toys used were quite different, they were both stacking toys. Future research should explore scaffolding with more diverse toy types to see if the identified consistency in scaffolding variables holds. Also, consistency in scaffolding across toys at different ages needs to be explored. For the present study, alternative toys were piloted for the 18- and 24-month time-points, but none could be successfully coded in a way that was comparable to the coding for the ring toy, primarily due to a diversity of possible goals. Once appropriate toys are identified that are amenable to coding, it should be possible to assess this type of consistency in scaffolding from 18 months and upwards. Nevertheless, as far as we are aware, this is the first study to examine consistency in scaffolding across toys with young children, and the results suggest this could be a fruitful avenue of research.

To assess the influence of scaffolding on children's effortful control, the present study looked at three scaffolding variables: propensity to scaffold, directiveness and contingency. There was no relationship between propensity to scaffold and effortful control. However, the fact that mothers' propensity to scaffold was relatively consistent over time and across toys, combined with the literature on the positive impact effective scaffolding can have on learning (Hammond et al. 2012; Wood et al. 1976), suggests that propensity to scaffold could have developmental effects which were not captured within the present study's scope. For example, it may be that the extent to which a mother chooses to scaffold affects aspects of psychological functioning that were not measured in the present study. Alternatively, it could be that propensity to scaffold plays a mediational role between other scaffolding variables and child outcomes: parents who engage in regular high-quality scaffolding may have a positive developmental impact compared to those who engage in regular low-quality scaffolding or occasional high-quality scaffolding. Studies with larger samples would be able to test such hypotheses using mediation analysis (MacKinnon et al. 2007). Given the identified relationship between maternal contingency and child outcomes, contingency would be an important variable to include in such analysis as a constituent part of high-quality scaffolding.

The developmental significance of contingency has been identified in research with older children (Pino-Pasternak and Whitebread 2010). With infants, when contingency is measured on a micro utterance-by-utterance level, studies have found effects on child performance during play, but limited evidence for an impact on broader child outcomes (Conner and Cross 2003). As discussed above, this may be because many studies using an utterancelevel approach to the analysis of scaffolding behaviour introduce noise into the data by failing to differentiate between actions directed towards different goals.

In the present study, using a coding scheme that distinguished three different goals, maternal contingency at 12-months was concurrently and predictively associated with the effortful control measures. The fact that only 12-month contingency predicted 24-month effortful control could be because of the limited time-scale of the study, and 18 and 24month contingency may have relations with effortful control at later ages. Alternatively, it could be because 12 to 24 months is a fundamental period for the emergence of effortful control and executive functions, and perhaps parental influences have the strongest effect earlier in this period (Garon et al. 2008). Also, the sequential analysis results showed that while 
contingent interventions at 12 and 18-months led to children's successful actions, contingent interventions at 24-months did not. This suggests that the developmental impact of maternal scaffolding may depend upon contingent interventions leading to improvements in child performance, and the level of challenge presented by the task needs to be at the appropriate level to facilitate such interaction. In the present study, the ring toy at 24-months may not have represented sufficient challenge for contingent support to exert any appreciable influence on children's performance (as shown by the sequential analysis), and, consequently, contingent interventions were unrelated to children's development. Contingent interventions may influence child development via their effect on children's immediate performance and learning during play. Note, however, that contingency had a much stronger relationship with effortful control than child performance (which only had a marginally significant correlation with delay task scores), meaning that it is the successful actions that occur as a result of contingent intervention, rather than successful actions in themselves, that predict development. Future research with larger samples could use structural equation modelling and path analysis to test this hypothesis.

The sequential analysis also showed that while contingent interventions led to successful child actions significantly more than non-contingent interventions, the reverse was also true: successful child actions led to contingent interventions (i.e. the withdrawal of support) significantly more than unsuccessful child actions. This suggests that dyads with contingent parents and successful children were engaged in a form of positive feedback loop where contingent interventions led to child success, and child success then led back to contingent interventions. This reflects the reciprocal, intrinsically intersubjective nature of scaffolding (Salonen et al. 2007), and is consistent with the recent findings of Klein et al. (2016) who identified a bidirectional relationship in preschool dyadic interaction whereby maternal behaviour influences child development and vice versa. The presence of such dyadic feedback loops represents both a challenge and an opportunity for intervention science: the challenge comes from the fact that positive developmental feedback loops mean that more capable children are more able to elicit and internalise effective parental intervention, and so become yet more capable, whereas at-risk children struggle to elicit or benefit from the kind of parental intervention which could improve their developmental outcomes. The opportunity comes from the fact that if such positive feedback loops can be understood and utilised as an intervention tool their self-reinforcing nature means they would represent a very powerful tool for positive developmental change that would need minimal maintenance (i.e. minimal retraining of parents over time, as initial changes in parent behaviour would lead to changes in child behaviour which would, in turn, reinforce parental behaviour). The potential of such interventions can be seen in the results of this study. Of the 6 children who were matched for belowthe-mean effortful control scores at 12-months, the 3 from the consistently contingent group improved in effortful control by a whole standard deviation over the year. Mothers high level of contingency at 12-months may have instigated a positive developmental feedback loop leading to this large improvement in outcomes. A task for future research is to identify when and how such feedback loops can be instigated in early development in at-risk populations.

When parents were grouped based on how consistent they were in their use of contingency over the year, the consistently contingent group had children who performed at higher levels on all measures of child psychological functioning: The Grasping Task at 12 months, The Bayley Scales of Infant Development at 18 months, and the Delay Tasks at 24 months. Therefore, although the discrete 18 and 24-month measures of contingency were unrelated to any of these variables, parental consistency in contingency from 12 to 24-months was 
related to all three of them. Again, this reflects findings regarding maternal sensitivity. Mothers who are consistent in their 'sensitive responding' over the first 4 years of their child's life have children who demonstrate faster rates of cognitive and social growth (Landry et al. 2003).

Although many studies have found negative associations between parental directiveness and child outcomes, it has been suggested that directiveness can have positive effects on learning depending on the current developmental stage of the learner (Masur and Turner 2001; Pine 1992). In the present study, directiveness at 12-months was correlated concurrently with the Grasping Task at 12-months. Given this was the only relationship identified between directiveness and effortful control, it needs to be treated cautiously and verified in future research. However, it is consistent with the idea that directive interventions are important for younger infants, because when infants understand very little explicit and clear instruction is likely to be required for them to succeed at any complex task (Pine 1992; Salonen et al. 2007), and there is evidence that greater parental directiveness is beneficial for preterm children compared to full-term children (van de WeijerBergsma et al. 2016). Such research findings indicate that directiveness needs to be applied contingently, taking account of the current developmental level and ability of the learner. When learning a new skill directive interventions may help establish fundamental abilities, but then directiveness needs to be gradually withdrawn as learners become more skilled and able to self-regulate. Directiveness can be important for toddlers' development of self-regulation but can be detrimental if parents continue to be directive from 3.5 years onwards (Landry et al. 2000).

In understanding the findings of the present study, it is likely that the particular challenges presented by the ring toy are an important factor. At 12-months infants are just beginning to use basic actions (ring placement) with the ring toy, and so directiveness is probably important for their learning. In particular, if a mother wants her 12-month old to place the rings in order she will have to be directive in indicating the correct next ring in sequence. By contrast, at 12 and 18-months infants can place rings and select rings independently, so mothers have less need to be directive. As with other findings, it could be the case that directiveness at 18 or 24 -months had effects beyond the timescale of the present study, but it seems more likely that any association between 12month directiveness and effortful control actually arose from the fact that the toys at 12-months represented the correct degree of challenge for directive interventions to be an appropriate form of scaffolding.

The results of this study suggest that maternal contingency during play in infancy could lay the foundations for the strategic regulation of cognition, attention and behaviour. It is possible that directive utterances at, and prior to, 12 months old may also help infants acquire fundamental skills in behaviour control through direct instruction, but more evidence is required to substantiate this tentative conclusion. A substantial caveat to these conclusions is that this study used a small sample of predominately middle-income British dyads, and whether these findings can be generalized to the wider population is an open question to be addressed in future research.

Infancy is an important developmental period for children's effortful control and selfregulation (Spinrad et al. 2012), and we are only just beginning to understand how these capacities emerge and the ways in which parental behaviour mediates or directs their development in the context of dyadic interaction. The results of this study contribute to our increasing understanding of the social contexts which foster the emergence of selfregulatory skills in infancy. 
Acknowledgements This research was funded by a PhD studentship award from the UK Economic \& Social Research Council (ESRC).

\section{Compliance with ethical standards}

Conflict of interest The authors declare that they have no conflict of interest.

Open Access This article is distributed under the terms of the Creative Commons Attribution 4.0 International License (http://creativecommons.org/licenses/by/4.0/), which permits unrestricted use, distribution, and reproduction in any medium, provided you give appropriate credit to the original author(s) and the source, provide a link to the Creative Commons license, and indicate if changes were made.

\section{References}

Austin, P. C., \& Steyerberg, E. W. (2015). The number of subjects per variable required in linear regression analyses. Journal of Clinical Epidemiology, 68, 627-636.

Bayley, N. (2006a). Bayley scales of infant and toddler development third edition: Administration manual. San Antonio, Texas: Pearson.

Bayley, N. (2006b). Bayley scales of infant and toddler development third edition: Technical manual. San Antonio, Texas: Pearson.

Bernier, A., Carlson, S. M., \& Whipple, N. (2010). From external regulation to self-regulation: Early parenting precursors of young children's executive functioning. Child Development, 81, 326-339. https://doi. org/10.1111/j.1467-8624.2009.01397.x.

Bernier, A., Carlson, S. M., Deschênes, M., \& Matte-Gagné, C. (2012). Social factors in the development of early executive functioning: A closer look at the caregiving environment. Developmental Science, 15, 12-24. https://doi.org/10.1111/j.1467-7687.2011.01093.x.

Bibok, M. B., Carpendale, J. I. M., \& Muller, U. (2009). Parental scaffolding and the development of executive function. New Directions in Child and Adolescent Development, 123, 17-34.

Conner, D. B., \& Cross, D. R. (2003). Longitudinal analysis of the presence, efficacy and stability of maternal scaffolding during informal problem-solving interactions. British Journal of Developmental Psychology, 21(3), 315-334. https://doi.org/10.1348/026151003322277720.

Conner, D. B., Knight, D. K., \& Cross, D. R. (1997). Mothers' and fathers's scaffolding of their 2-year-olds during problem-solving and literacy interactions. British Journal of Developmental Psychology, 15(3), 323-338. https://doi.org/10.1111/j.2044-835X.1997.tb00524.x.

Conway, A., \& Stifter, C. A. (2012). Longitudinal antecedents of executive function in preschoolers. Child Development, 83, 1022-1036. https://doi.org/10.1111/j.1467-8624.2012.01756.x.

Cuevas, K., Deater-Deckard, K., Kim-Spoon, J., Watson, A. J., Morasch, K. C., \& Bell, M. A. (2014). What's mom got to do with it? Contributions of maternal executive function and caregiving to the development of executive function across early childhood. Developmental Science, 17, 224-238. https://doi.org/10.1111 /desc.12073.

Eisenberg, N., Smith, C. L., \& Spinrad, T. L. (2004). Effortful control: Relations with emotion regulation, adjustment, and socialization in childhood. In Handbook of self-regulation: Research, theory, and applications. (pp. 259-282).

Garon, N., Bryson, S. E., \& Smith, I. M. (2008). Executive function in preschoolers: A review using an integrative framework. Psychological Bulletin, 134(1), 31-60. https://doi.org/10.1037/00332909.134.1.31.

Gelman, A., Hill, J., \& Yajima, M. (2012). Why we (usually) don't have to worry about multiple comparisons. Journal of Research on Educational Effectiveness, 5, 189-211.

Green, S. B. (1991). How many subjects does it take to do a regression analysis? Multivariate Behavioral Research, 26(3), 499-510.

Hammond, S. I., Müller, U., Carpendale, J. I. M., Bibok, M. B., \& Liebermann-Finestone, D. P. (2012). The effects of parental scaffolding on preschoolers' executive function. Developmental Psychology, 48(1), 271281. https://doi.org/10.1037/a0025519.

Hughes, C., \& Ensor, R. (2009). How do families help or hinder the emergence of early executive function? New Directions for Child and Adolescent Development, 123, 35-50. https://doi.org/10.1002/cd.234. 
Jaffee, S. R. (2007). Sensitive, stimulating caregiving predicts cognitive and behavioral resilience in neurodevelopmentally at-risk infants, 19(3), 631-647. https://doi.org/10.1017/S0954579407000326.

Karreman, A., Van Tuijl, C., \& Marcel, A. G. (2006). Parenting and self-regulation in preschoolers : A metaanalysis. Infant and Child Development, 579, 561-579. https://doi.org/10.1002/icd.

Klein, M. R., Lengua, L. J., Thompson, S. F., Moran, L., Ruberry, E. J., Kiff, C., \& Zalewski, M. (2016). Bidirectional relations between temperament and parenting predicting preschool-age children's adjustment. Journal of Clinical Child \& Adolescent Psychology, 47, 1-14. https://doi.org/10.1080 /15374416.2016.1169537.

Kochanska, G., \& Aksan, N. (2004). Development of mutual responsiveness between parents and their young children. Child Development, 75(6), 1657-1676. https://doi.org/10.1111/j.1467-8624.2004.00808.x.

Kochanska, G., \& Boldt, L. J. (2013). Effortful control batteries manual. USA: The University of Iowa.

Kochanska, G., Murray, K. T., \& Harlan, E. T. (2000). Effortful control in early childhood: Continuity and change, antecedents, and implications for social development. Developmental Psychology, 36(2), $220-232$.

Kochanska, G., Aksan, N., Prisco, T. R., \& Adams, E. E. (2008). Mother-child and father-child mutually responsive orientation in the first 2 years and children's outcomes at preschool age: Mechanisms of influence. Child Development, 79(1), 30-44. https://doi.org/10.1111/j.1467-8624.2007.01109.x.

Kok, R., Bakermans-Kranenburg, M. J., van IJzendoorn, M. H., Velders, F. P., Linting, M., Jaddoe, V. W. V. ... Tiemeier, H. (2012). The role of maternal stress during pregnancy, maternal discipline, and child COMT Val158Met genotype in the development of compliance. Developmental Psychobiology, 55(5), 451-464.

Landry, S. H., Smith, K. E., Miller-Loncar, C. L., \& Swank, P. R. (1997). Predicting cognitive-language and social growth curves from early maternal behaviors in children at varying degrees of biological risk. Developmental Psychology, 33(6), 1040-1053. Retrieved from http://www.ncbi.nlm.nih. gov/pubmed/9383626.

Landry, S. H., Smith, K. E., Swank, P. R., \& Miller-loncar, C. L. (2000). Early maternal and child influences on children's later independent cognitive and social functioning. Child Development, 71(2), 358-375.

Landry, S. H., Smith, K. E., Swank, P. R., Assel, M. A., \& Vellet, S. (2001). Does early responsive parenting have a special importance for children's development or is consistency across early childhood necessary? Developmental Psychology, 37(3), 387-403. Retrieved from http://www.ncbi.nlm.nih. gov/pubmed/11370914.

Landry, S. H., Smith, K. E., \& Swank, P. R. (2003). The importance of parenting during early childhood for school-age development. Developmental Neuropsychology, 24(2-3), 559-591. https://doi.org/10.1080 /87565641.2003.9651911.

Lengua, L. J., Kiff, C., Moran, L., Zalewski, M., Thompson, S., Cortes, R., \& Ruberry, E. (2014). Parenting mediates the effects of income and cumulative risk on the development of effortful control. Social Development, 23(3), 631-649.

Lewis, C., \& Carpendale, J. I. M. (2009). Introduction: Links between social interaction and executive function. In C. Lewis \& J.I.M. Carpendale (Eds.), social interaction and the development of executive function. New Directions for Child and Adolescent Development, 123, 1-16.

MacKinnon, D. P., Fairchild, A. J., \& Fritz, M. S. (2007). Mediation analysis. Annual Review of Psychology, 58, 593-614. https://doi.org/10.1146/annurev.psych.58.110405.085542.

Matte-Gagné, C., \& Bernier, A. (2011). Prospective relations between maternal autonomy support and child executive functioning: Investigating the mediating role of child language ability. Journal of Experimental Child Psychology, 110(4), 611-625. https://doi.org/10.1016/j.jecp.2011.06.006.

Masur, E. F, \& Turner, M. (2001). Stability and consistency in mothers' and infants' interactive styles. MerrillPalmer Quarterly, 47(1), 100-120

Mischel, W., \& Baker, N. (1975). Cognitive appraisals and transformations in delay behavior. Journal of Personality and Social Psychology, 31(2), 254-261. https://doi.org/10.1037/h0076272.

Nakagawa, S. (2004). A farewell to Bonferroni: The problems of low statistical power and publication bias. Behavioral Ecology, 15, 1044-1045.

Neale, D., \& Pino-Pasternak, D. (2016). A review of reminiscing in Early Childhood settings and links to sustained shared thinking. Educational Psychology Review, 1-25. https://doi.org/10.1007 /s10648-016-9376-0.

Neale, D., Basilio, M., \& Whitebread, D. (2018). The grasping task: A 12-month predictor of 24-month delay task performance and BRIEF-P inhibition scores. Infant and Child Development, 27(4). https://doi. org/10.1002/icd.2092.

Nordling, J. K., Boldt, L. J., O’Bleness, J., \& Kochanska, G. (2016). Effortful control mediates relations between children's attachment security and their regard for rules of conduct. Social Development, 25(2), $268-284$. https://doi.org/10.1111/sode.12139.

Perneger, T. V. (1998). What's wrong with Bonferroni adjustments. British Medical Journal, 316, 1236-1238. 
Pine, J. M. (1992). Maternal style at the early one-word stage: Re-evaluating the stereotype of the directive mother. First Language, 12(35), 169-186. https://doi.org/10.1177/014272379201203504.

Pino-Pasternak, D., \& Whitebread, D. (2010). The role of parenting in children's self-regulated learning. Educational Research Review, 5(3), 220-242. https://doi.org/10.1016/j.edurev.2010.07.001.

Pino-Pasternak, D., Whitebread, D., \& Tolmie, A. (2010). A multidimensional analysis of parent-child interactions during academic tasks and their relationships with Children's self-regulated learning. Cognition and Instruction, 28(3), 219-272. https://doi.org/10.1080/07370008.2010.490494.

Rudek, D. J., \& Haden, C. A. (2005). Mothers' and preschoolers' mental state language during reminiscing over time. Merrill-Palmer Quarterly, 51(4), 523-549.

Salonen, P., Lepola, J., \& Vauras, M. (2007). Scaffolding interaction in parent-child dyads: Multimodal analysis of parental scaffolding with task and non-task oriented children. European Journal of Psychology of Education, 22(1), 77-96. https://doi.org/10.1007/BF03173690.

Spinrad, T. L., Eisenberg, N., Silva, K. M., Eggum, N. D., Reiser, M., Edwards, A., et al. (2012). Longitudinal relations among maternal behaviors, effortful control and young children's committed compliance. Developmental Psychology, 48(2), 552-566.

Vallotton, C. D. (2009). Do infants influence their quality of care? Infants' communicative gestures predict caregivers' responsiveness. Infant Behavior \& Development, 32(4), 351-365. https://doi.org/10.1016/j. infbeh.2009.06.001.

Vallotton, C., \& Ayoub, C. (2011). Use your words: The role of language in the development of toddlers' selfregulation. Early Childhood Research Quarterly, 26(2), 169-181. https://doi.org/10.1016/j. ecresq.2010.09.002.

van de Weijer-Bergsma, E., Wijnroks, L., van Haastert, I. C., Boom, J., \& Jongmans, M. J. (2016). Does the development of executive functioning in infants born preterm benefit from maternal directiveness? Early Human Development, 103, 155-160. https://doi.org/10.1016/j.earlhumdev.2016.09.012.

Van der Mark, I. L., Bakermans-Kranenburg, M. J., \& Van Ijzendoorn, M. H. (2010). The role of parenting, attachment, and temperamental fearfulness in the prediction of compliance in toddler girls. British Journal of Developmental Psychology, 20(3), 361-378.

Vygotsky, L. (1962). Thought and language. Cambridge, MA: MIT Press.

Vygotsky, L. (1978). Mind in society: The development of higher psychological processes. Cambridge, MA: Harvard University Press.

Wertsch, J. V. (1979). From social interaction to higher psychological processes. Human Development, 22, 1-22.

Wertsch, J. V. (1993). Voices of the mind: A sociocultural approach to mediated action. Cambridge, MA: Harvard University Press.

Wertsch, J. V. (1998). Mind as action. Oxford: Oxford University Press.

Winsler, A., Diaz, R. M., \& Montero, I. (1997). The role of private speech in the transition from collaborative to independent task performance in young children. Early Childhood Research Quarterly, 22, 215-231.

Wood, D. J., \& Middleton, D. (1975). A study of assisted problem-solving. British Journal of Psychology, 66, 181-191.

Wood, D., Bruner, J. S., \& Ross, G. (1976). The role of tutoring in problem solving. Journal of Child Psychology and Psychiatry, 17(2), 89-100. https://doi.org/10.1111/j.1469-7610.1976.tb00381.x.

Publisher's note Springer Nature remains neutral with regard to jurisdictional claims in published maps and institutional affiliations. 